\title{
CUENTA DI NANZI
}

DOOR

M. D. LATOUR

V

GOD EN HET KONIJNTJE (DIOS Y COMPA CONENCHI) 1)

In vroegere tijden had het konijntje niet de lange oren, die het nu heeft. Op zekere dag ging het konijntje naar God en vroeg of God zijn oren even groot kon maken als zijn lichaam.

God kon en wilde dat, maar eiste, dat het konijntje hem eerst de baard van een leeuw en het mondslijm van een tijger zou brengen.

Het konijntje ging op weg en bond zich in een bos vast aan een boom. Cha Leon, de leeuw, kwam voorbij en zag het konijntje aan de boom vastzitten.

"Wat heeft dat te beteekenen", vroeg de leeuw achterdochtig.

"Wel, Cha Leon", zei het konijntje, ,er is me gezegd ,dat er een orkaan op komst is".

$\mathrm{Nu}$ was de deeuw dodelijk benauwd voor een orkaan; daarom smeekte hij het konijntje hem eerst stevig aan een boom te binden, want hij kon het zelf niet.

"Goed", zei het konijntje en het maakte zich los om vader leeuw stevig aan de boom vast te snoeren. Toen trok het zijn mes en sneed den leeuw zijn baard af.

Deze begreep toen, dat hij er in gevlogen was, en tierde hemel en aarde bij elkaar, maar het konijn liet hem rustig zitten.

Verderop in een herberg trof het konijn Cha Tiger, die enigszins boven zijn theewater was.

Het konijn wenkte hem apart en fluisterde hem met een echte treurstem in de oren: „Van harte gecondoleerd, Cha Tiger”.

1) Gobi is een bakje bestaande uit de halve bast van een kalabas. 
De tijger schrok zich half dood. „Waarmee?” vroeg hij angstig.

„Ik ben net langs het huis van Cha Tiger gekomen en daar vernam ik dat Cha Tiger zijn vrouw plotseling gestorven is". -

Toen brak de tijger in een wild geschrei uit en hij huilde zo heftig, dat het mondslijm hem over de kin liep.

Het konijntje nam toen een gobi ${ }^{1}$ ) en hield dat onder de kin van den tijger.

Daarna hastte hij zich de deur uit en rende naar God. Deze zag de gestelde voorwaarde vervuld en schonk het konijntje de lange oren, die alle konijntjes tegenwoordig hebben.

\section{NANZI EN DE SLANG BARBAQUINA (NANZI Y COLEBRA BARBA- QUINA)}

Comader Barbaquina had Pegasaya, den jongsten zoon van papa Nanzi, ten doop gehouden en was dus zijn madrina (peettante). Barbaquina nu kon zeer goed koken en als een liefhebbende madrina zond zij nu en dan enige lekkere „,arepa di mainshi chiquito"' (pannekoekjes van kleine mais) aan Compader Nanzi en Ihá (petekind) Pegasaya. Nanzi was zo dol op deze koekjes, dat hij niets anders meer wilde voor zijn middagmaal. Hij kwam dagelijks langs het huis van Comander Barbaquina, die voor veel arbeiders kookte en bakte, zodat zij ook dagelijks arepa in voorraad had.

Nanzi had namelijk een karwei gekregen in de knoek van Shon Arey. Hij moest iedere dag mest van koeien en geiten kruien en op een hoop bijeen brengen in een hoek achter in de knoek van den koning. Iedere dag, als hij langs het winkeltje van Barbaquina kwam, leende hij voor twee real 2) pannekoek. Nanzi noemde dat lenen: feitelijk kocht hij ze, maar zonder te betalen.

Zo nu en dan, als Comader Barbaquina hem weer eens dringend gemaand had tot betalen, sloeg hij twee of drie dagen over. Dat wil zeggen, dat hij dan zelf niet ging, maar Pegasaya of Shi Maria er op af stuurde.

1) Eigenlijk behoort dit verhaal tot een andere cyclus, waarin niet de Spin, maar het Konijn telkens de hoofdrol speelt. Vooral op Aruba schijnen verschillende Konijnverhalen in omloop te zijn. Daar spreekt men echter niet van Compa Conenchi, maar van Cha Coneeuw (Tio of Tia Conejo; Spaans: Konijn).

2) Een real, of riá, zoals het volk zegt, is vijftien cent. 
De ene maand na de andere ging voorbij en Nanzi betaalde maar niet.

Op zekere dag had Barbaquina er genoeg van en besloot Nanzi te doden en al zijn geld in beslag te nemen.

Dit kwam Nanzi ter ore en spoedig had hij zijn maatregelen genomen. Hij klopte aan bij moeder geit en verzocht haar in zijn huis te komen slapen, want hij voelde zich zeer ziek en het kon best van nacht met hem mislopen. Daarbij trok Nanzi zo'n erbarmelijk gezicht en liep hij zo krom en scheef, dat de geit overtuigd was, dat hij vreselijke pijnen leed. Uit medelijden met den stakker beloofde ze in zijn huis te komen slapen.

's Avonds kwam de geit inderdaad en Nanzi lag al in bed. Hij verzocht de geit vlak achter de deur te gaan liggen, want dan kon zij dadelijk open doen, als de dokter kwam.

Tegen kwart voor twaalf kreunde Nanzi op zijn best: oe-oe-oe, ay, au, o verschrikkelijk, au, au, au!!

De geit schrok wakker: „Wat is er aan de hand?”

„Oooooooo!!! vreselijke pijn”, jammerde Nanzi; „let op, daar komt juist de dokter".

De geit opende de deur in het nachtelijk duister op een kier, maar dat was juist voldoende voor de slang Barbaquina om haar kop door te steken en blindelings te bijten met haar giftanden.

De geit stierf spoedig en Nanzi haalde de ingewanden er uit en hing deze te drogen in de zon.

De volgende middag ging Nanzi weer met een brutaal gezicht voor twee real pannekoek kopen, maar natuurlijk zonder te betalen. Barbaquina's ogen puilden uit haar hoofd. „Is dat niet Nanzi, die ik gisteren gedood heb?"

„Als je me een beetje dieper gebeten had, zou ik het wel gevoeld hebben", zei Nanzi met een onverschillig gezicht.

Kort daarop wilde de slang een nieuwe poging wagen om Nanzi te doden, maar ook deze keer mislukte haar toeleg, doordat Nanzi kans had gezien een koe te bedriegen op de zelfde wijze als hij eerst de geit bedrogen had.

Toen Barbaquina voor de derde maal haar geluk beproefde, nodigde Nanzi een aap uit, om bij hem te komen slapen.

Maar apen zijn óók slimme rakkers en toen Nanzi om kwart voor twaalf zijn gewone jammerpartij inzette en de aap waarschuwde, dat de dokter op komst was, klom deze vlug in de hanebalken.

Toen Nanzi zei, dat hij voor de deur moest blijven slapen, ant- 
woordde de aap, dat hij rheumatiek had in zijn poten en dat het zo tochtte onder de deur door.

Toen kwam Colebra Barbaquina, brak de deur open en doodde Nanzi....

Sinds die dag had Barbaquina voor eens en voor altijd genoeg van arepa di maïnshi chiquito en verkocht voortaan arepa van pompoenen.

\section{NANZI, ZEZE EN TRAGABINA (NANZI, ZEZE Y TRAGABINÁ) 1)}

Op zekere dag zond Compa Nanzi zijn jongste zoon, Pegasaya, naar zijn oom Zeze om een beetje vuur te halen. Compa Zeze was juist bezig arepa van pompoen te bakken met eieren erin. Zeze gaf zijn neefje Pegasaya een pannekoekje en een beetje vuur en deze ging naar huis.

Thuis vond hij papa Nanzi ingedut op de grond. Hij liep heel zachtjes en hield de arepa onder de neus van Nanzi.

Deze vloog overeind en sloeg zijn jongen. Het kind schreeuwde en riep: „Als u me slaat, krijgt u niets van de arepa”.

Juist op dat oogenblik viel Nanzi's oog op de arepa. Hij rukte de lekkernij uit de hand van zijn kind en at het op. Toen het hele pannekoekje veilig door zijn keelgat was, deelde hij Pegasaya mede, dat zo iets vergif was voor kleine kinderen.

„Waarom kan u het dan wél eten", vroeg de kleine rakker.

Papa beantwoordde deze vraag van zoonlief met een klinkende oorvijg en besloot meteen zelf eens naar Compa Zeze te gaan, om te weten te komen, waar Zeze al die eieren vandaan haalde.

Zeze vertelde hem, dat hij ze iedere morgen ging stelen in het huis van de slang Tragabiná.

$Z_{i j}$ hielden samen een lange bespreking en kwamen ten slotte overeen, dat Nanzi de volgende keer met Zeze mee zou gaan.

Compa Nanzi ging naar huis. Heel vroeg in de morgen stond Nanzi al veel te vroeg op en begon te kraaien als een haan, maar Zeze sliep rustig door tot het tijd was. Nanzi stond al klaar met een ezel en drie lege kerosineblikken ${ }^{2}$ ) om een flinke voorraad in de wacht te slepen.

Klokslag vier gingen ze op stap en toen ze aangekomen waren, zei Zeze: „Bon dia” (goede morgen), en de deur van het slangenhuis ging open. Ze traden binnen :,Boquito” (mondje toe) en de deur ging weer dicht. Het was doodstil in huis.

1) Typisch voorbeeld van moderne inslag in de oude sprookjes.

2) Tragabiná betekent letterlijk: die een hert kan doorslikken. 
Zeze vulde zijn zak en Nanzi zijn drie blikken en ze begaven zich huiswaarts. Bij het vertrek moest men echter andere woorden gebruiken. Bij „bon dia” ging de deur weer open, maar om hem weer dicht te krijgen moest men nu zeggen: „bon noche” (goede avond).

Nanzi vond dat een buitengewoon aangename kostwinning en zette het bedrijf voort.

Op zekere dag meende Colebra Tragabiná, dat zij de laatste tijd opvallend schaars in haar eieren zat. Daar moest diefstal achter zitten. $\mathrm{Zij}$ besloot de wacht te houden.

De volgende morgen ging Nanzi weer, maar deze keer met twee ezels in plaats van een, want zijn gulzigheid is mateloos.

Alles ging als naar gewoonte. Nanzi groette de deur en deze opende zich van zelf. Hij trad binnen: „Boquito”, en de deur ging geruisloos toe. Spoedig was Nanzi verdiept in het eieren verzamelen, toen.... zag hij goed?.... de deur langzaam en zonder het minste gerucht weer open ging en de slang binnensloop! Nanzi dacht dat hij versteende van schrik en toen hij zijn spraakvermogen weer terugkreeg, begon hij te roepen: „Bon dia,7 bon noche, boquito," enz., zodat de deur niet meer wist wat zij doen moest.

Eindelijk had Nanzi voldoende zelfbeheersching om te zeggen: „Bon dia, lieve deur, ga alsjeblieft een klein beetje open, dat ik even naar buiten kan spuwen, want ik heb last van slijm in mijn keel".

De deur stond nauwelijks op een kier of Nanzi sloop naar buiten. Van die dag af liep hij altijd een straatje om, als hij Tragabiná zag aankomen, maar Zeze ging rustig door met eieren stelen, zonder dat de slang het merkte.

\section{PAPA NANZI EN BAAS TIJGER (COMPA NANZI Y CHA TIGER)}

In het jaar 1611, toen papa Nanzi juist zijn studies in de wijsheid achter de rug had, ging hij op weg naar huis.

Het eerste avontuur liet niet lang op zich wachten. Baas Tijger, die rammelde van de honger, lag al uren op iets eetbaars te wachten en likte zich de baard bij de nadering van Nanzi.

Nanzi dacht, dat zijn hart stilstond, toen hij den tijger zag naderen met een uiterst vriendelijk gezicht, maar hij begreep heel goed, dat het geen nut had om weg te loopen, daar baas Tijger toch veel harder lopen kon, dan hij. Wie niet sterk was, moest dus weer slim zijn. Nanzi zon op een list. 
Vlakbij was een grote regenbak; Nanzi liep, wat hij lopen kon en toen hij bij de regenbak aankwam, deed hij alsof hij uit alle macht tegen de muur van de bak stond te duwen.

De tijger zag hem bezig en vroeg achterdochtig: „Zeg eens, vriend Nanzi, wat sta jij daar tegen die regenbak te duwen? Scheelt het je in je bovenkamer?"

„Pas op! Pas op! riep Nanzi met prachtig geveinsde angst, „maak dat je wegkomt, tijger, want de muur staat op het punt om in te storten. Het zal je je leven kosten! En wat het ergste is: de bak is vol water".

$\mathrm{Nu}$ had de tijger zijn leven lief en stond niet op vriendschappelijke voet met water. Hij vond het dus maar verstandiger om heen te gaan. Maar dat was de bedoeling niet van papa Nanzi.

Juist had de tijger zich omgedraaid om door te lopen, toen Nanzi, die nog een veel fijnere grap wilde beleven, hem terugriep en angstig gilde: „Baas Tijger.... help!... loop nu niet weg! Ik voel, dat ik de muur niet langer alleen kan houden. Jij bent sterk; kom me even helpen, gauw, gauw! Als de muur valt, verdrinken we alle twee!"

Baas Tijger voelde zich gevleid, dat men een beroep deed op zijn grote spierkracht. Hij kwam aanstonds aanlopen en duwde met al zijn kracht, om de rand staande te houden.

„Prachtig, prachtig!” prees Nanzi, die zijn list wondergoed zag gelukken, „,wees nu niet bang en blijf even staan, dan ga ik dadelijk een metselaar halen om de muur te herstellen".

Toen dacht Nanzi: Ik heb mijn benen niet voor niets gekregen. Hij zette het op een lopen en, in zijn dorp aangekomen, heeft hij een kwartier lang staan brullen van het lachen.

Ik zei, dat dit gebeurde in 1611 . Het is nu 1938 en als de tijger intussen nog niet van honger en ouderdom gestorven is, staat hij nog altijd tegen de muur van de regenbak te duwen.

MENEER DE TIJGER EN MENEER NANZI (CHA TIGER Y CHA NANZI)

Meneer Tijger had een stukje grond gekocht, waarop veel awacátibomen 1) stonden, zwaar met vruchten beladen. Hij hield ijverig de wacht bij zijn bomen om de vruchten te plukken, als ze rijp zouden zijn.

1) De awacáti of alligatorpeer is een glimmende, donkergroene vrucht, veel gelijkend op een grote peer, maar met een stugge, harde schil en één zeer grote pit. In het Spaans schrijft men aguacate. 
Dicht bij hem woonde Meneer Nanzi. Op zekere dag stuurde deze zijn zoontje om een beetje vuur te gaan lenen bij meneer Tijger.

Deze gaf het gevraagde en voegde er voor den kleine een stukje awacáti bij, maar hij voegde er aan toe: „Niet aan je vader zeggen hoor, dat je die awacáti van mij hebt!"

Het jochie ging naar huis, maar in plaats van de awacáti op te eten, bewaarde hij het stukje vrucht onder zijn tong. Thuis gekomen, holde hij naar zijn vader en zei: „Vader, geef me een zoentje".

Zijn vader gaf hem een kus en kreeg de lucht van de awacati in zijn neus. Aanstonds vroeg hij aan zijn jongen: „Waar heb je die lekkere vrucht vandaan?"

„Die heeft meneer Tijger me gegeven”, antwoordde het kind.

Cha Nanzi stapte dadelijk naar den tijger en vroeg hem: „Shon Tijger, waar haal je die heerlijke vruchten vandaan?"

Shon Tijger gaf er een aan Cha Nanzi, die hem achter elkaar opat.

„Morgen gaan we samen awacáti plukken”, zei de tijger, „en dan delen we de buit samen".

"Goed”, zei Nanzi.

Zonder zich verder te bedenken, ging Cha Nanzi ogenblikkelijk naar een smid en vroeg deze, aanstonds een flinke ijzeren bal voor hem te maken. De volgende morgen was Nanzi al vroeg aan de smidse om zijn kogel af te halen en stak hem in zijn zak.

Daarop ging hij naar den tijger en beide begaven zich naar de boomgaard. Daar vroeg de tijger: „Wie zal in de boom klimmen?"

„Ik", zei Nanzi.

Cha Nanzi klom in de boom en begon de vruchten naar beneden te werpen. De tijger, die beneden stond, raapte ze op en legde ze op een hoop.

Plotseling riep Nanzi: „Shon Tijger, hier heb ik een grote; die kan je zo niet opvangen; ga een beetje achteruit en houd je mond open".

De tijger deed, zoals Nanzi hem zeide. Cha Nanzi haalde toen de kogel uit zijn zak en wierp hem zo hard in de bek van de tijger, dat deze bewusteloos achterover viel.

Toen daalde Nanzi, vlug als een kat, uit de boom, raapte alle vruchten bij elkaar en draafde er mee naar huis. 
NANZI'S WEDDINGSCHAP (UN PUSTAMENTO DI NANZI)

Op zekere dag ontmoette Nanzi twee deftige heren, die hem voor den gek hielden. Nanzi liet ze rustig hun gang gaan.

Hij wist dat de heren beide groothandelaars waren en goede zaakjes maakten, en zeide ten slotte: „De heren houden me voor den gek, omdat ik maar een arme, domme kerel ben. Maar ik neem niettemin de vrijheid de heren een weddingschap voor te slaan, nl. dat geen van beide heren in staat is, mij drie woorden achtereen, na te zeggen, die ik eerst zal voorzeggen. Ik wed om een peséta".

Beide schoten in een luide lach en namen de weddingschap aan. $\mathrm{Ze}$ wilden zelfs een peso betalen, tegen een peséta van Nanzi, indien deze verloor. Nanzi maakte een sierlijke buiging en zei:

„Tot uw dienst, mijne heren!"

Nanzi begon: Watapana (wilde dividivi).

De heer A herhaalde: Watapana.

Nanzi: Sambarco (sandaal).

De heer A: Sambarco.

„Verkeerd”, riep Nanzi en sloeg zijn twee armen in de lucht. De heer A dacht een ogenblik na en vroeg eindelijk: „Waarom? Ik heb toch alles precies nagezegd?"

„Nee, mijnheer heeft verloren”, zei Nanzi en hij haalde een krijtje uit zijn zak om met een streep op tafel zijn eerste overwinning aan te merken.

„Wel, dan moet ik het nog eens proberen”, zei mijnheer A.

„Goed”, zei Nanzi, „ik ben geheel en al tot uw dienst”. En voor de tweede maal begon Nanzi: Shimaruco (lijkt op een kersenboom).

En mijnheer A herhaalde: Shimaruco.

Nanzi: Chuchúbi (vogeltje).

De heer A: Chuchúbi.

En lachend riep Nanzi: Verkeerd!

Mijnheer A spalkte zijn ogen wijd open en zei: „Maar dáár begrijp ik niets van".

„Neen, mijnheer, u hebt voor de tweede keer verloren”, zei Nanzi en hij haalde zijn krijt voor den dag om nog een streep op tafel te zetten.

Zo hield Nanzi het vol tot vijf keer achter elkaar.

$\mathrm{Nu}$ mijnheer A al vijf peso verloren had, verging hem langzamerhand de lust om door te gaan, maar nu stond mijnheer B op om zijn geluk te beproeven en te zien of hij het misschien winnenkon. 
Nanzi begon: Shonchorogay (vogeltje).

Mijnheer B: Shonchorogay.

Nanzi: Warawara (roofvogel).

Mijnheer B: Warawara.

Nanzi: Verkeerd, mijnheer!

Mijnheer B: Niet waar!

Hanzi: Toch wel mijnheer, $\mathrm{u}$ hebt verloren; en Nanzi haalde zijn krijtje weer uit zijn zak en begon aan een nieuwe rij streepjes.

„Nu, vooruit dan maar, dan doe ik het nog eens over, net zo lang tot ik het win".

Nanzi lachte tevreden: „Tot uw dienst, mijnheer”.

En hij begon opnieuw: Catibo (slaaf).

Mijnheer B herhaalde: Catibo.

Nanzi: Gobierno (Gouvernement).

Mijnheer B: Gobierno.

Nanzi schudde zijn hoofd: Verkeerd!

Mijnheer B: Pardon, het is goed!

Nanzi: Neem me niet kwalijk, mijnheer, u heeft het helemaal verloren; en weer volgde een streepje op tafel.

Voor de derde keer begon Nanzi: Chobolobo.

Mijnheer B: Chobolobo (naam van een stuk grond op Curaçao).

Nanzi: Schottegat (haven van Willemstad).

Mijnheer B: Schottegat.

Nanzi wreef zich verheugd in de handen en zeide: Verkeerd!

Mijnheer B: Gemene leugenaar die je bent! Het was helemaal goed!

Nanzi: Nee, mijnheer, $u$ hebt het verloren!

De heer B wond zich hoe langer hoe meer op en toen er al vijf streepjes van hem op tafel stonden, begon Nanzi nog een keer:

Cocojoco (kukeleku).

De heer B: Cocojoco.

Nanzi: Caramba (verdikkie).

De heer B: Caramba.

Nanzi lachte fijntjes en zei: Verkeerd!

De heer B: Verkeerd? Wat?

„Nu heeft $\mathrm{u}$ het gewonnen en ik heb het verloren. Alstublieft, hier is uw peseta".

De twee heren keken elkaar verbluft aan. Ze begrepen zelf niet eens, waarom ze het nu eigenlijk gewonnen hadden. Ze vroegen Nanzi uitleg van zijn truc.

„Heel eenvoudig”, zei Nanzi, „het derde woord was telkens 
„verkeerd”, maar de heren herhaalden dat woord geen een keer, behalve mijnheer B de laatste keer. Daarom heb ik van elk van de heren vijf peso gewonnen en aan mijnheer B één peseta verloren. Ik blijft altijd tot uw dienst, mijne heren!"

N.B. 1. Een peso (stuk) is een Spaanse munt. De peso de oro (goudstuk) had een waarde van $f 2,50$. De peséta (stukje) was $f 0.50$ (100 centimos).

N.B. 2. Dit sprookje draagt een modern karakter. Is zeker niet van Afrikaanse oorsprong.

West-Indische Gids XX 